Tropical Journal of Pharmaceutical Research January 2021; 20 (1): 41-46

ISSN: $1596-5996$ (print); 1596-9827 (electronic)

(C) Pharmacotherapy Group, Faculty of Pharmacy, University of Benin, Benin City, 300001 Nigeria.

\title{
Effect of miR-200c on nasopharyngeal carcinoma and the probable molecular regulatory mechanism involved
}

\author{
Sheng $\mathrm{Xu}^{1}$, Wenxia $\mathrm{He}^{2 *}$ \\ ${ }^{1}$ Department of Otorhinolaryngology, Maternal and Child Health Hospital of Hubei Province, Wuhan 430070, ${ }^{2}$ Department of \\ Otorhinolaryngology, The People's Hospital of China Three Gorges University \& The First People's Hospital of Yichang, \\ Yichang 443000, PR China
}

*For correspondence: Email: ugytop@163.com

\begin{abstract}
Purpose: To determine the effect of micro-ribonucleic acid-200c (miR-200c) on biological function of nasopharyngeal carcinoma, and the likely molecular regulatory mechanism involved.

Methods: Thirty (30) nasopharyngeal carcinoma tissues and para-cancerous normal tissues were taken from patients undergoing surgery in Maternal and Child Health Hospital of Hubei Province, Wuhan from September 2018 to January 2020. The expression levels of miR-200c in the two types of tissues were determined. Cells of human nasopharyngeal carcinoma cell line HNE1 were cultured to about $70 \%$ growth prior to transfection with blank plasmid, PINI and miR-200c analogs. After $48 \mathrm{~h}$ of culture, control group, PINI group, and miR-200c over-expression + PINI group were obtained. The expression levels of $\mathrm{PINI}$ and changes in centrosomes in each group were measured, and changes in cell migration in each group were determined using Transwell migration assay.

Results: Compared with para-cancerous normal tissues, the expression level of miR-200c in nasopharyngeal carcinoma was significantly increased $(p<0.01)$. Compared with the control group, the PINI expression level and cell migration ability in miR-200c overexpression tissue were markedly decreased, while the percentage of extra centrosomes was markedly increased. Compared to miR-200c over-expression tissue, the PINI expression level and cell migration ability in the miR-200c overexpression + PINI group were markedly raised, while the percentage of extra-central somatic cells was significantly decreased $(p<0.05)$.

Conclusion: MiR-200c may inhibit the migration of nasopharyngeal carcinoma cells by inhibiting the expression of PINI and inhibiting abnormal expansion of centrosomes.
\end{abstract}

Keywords: MiR-200c, Nasopharyngeal carcinoma, Biological function, Molecular regulatory mechanism

\begin{abstract}
This is an Open Access article that uses a fund-ing model which does not charge readers or their institutions for access and distributed under the terms of the Creative Commons Attribution License (http://creativecommons.org/licenses/by/4.0) and the Budapest Open Access Initiative (http://www.budapestopenaccessinitiative.org/read), which permit unrestricted use, distribution, and reproduction in any medium, provided the original work is properly credited.
\end{abstract}

Tropical Journal of Pharmaceutical Research is indexed by Science Citation Index (SciSearch), Scopus, International Pharmaceutical Abstract, Chemical Abstracts, Embase, Index Copernicus, EBSCO, African Index Medicus, JournalSeek, Journal Citation Reports/Science Edition, Directory of Open Access Journals (DOAJ), African Journal Online, Bioline International, Open-J-Gate and Pharmacy Abstracts

\section{INTRODUCTION}

Nasopharyngeal carcinoma is a tumor that originates from the mucosal epithelium of the nasopharynx. It often occurs in the pharyngeal crypt and top forearm of the nasopharynx, and it is one of the most common head-and-neck malignant tumors in South China and Southeast Asia. The factors involved in the pathogenesis of nasopharyngeal carcinoma are not fully understood. However, it is currently generally believed that the pathogenesis of 
nasopharyngeal carcinoma is related to genetic susceptibility, environmental factors, and latent infection with EB virus. Nasopharyngeal carcinoma may result from gene-environment-EB virus interactions [1]. One of the main treatment methods currently used for nasopharyngeal carcinoma is chemotherapy. However, the 5-year survival after using chemotherapy alone is only about $50 \%$. Although the therapeutic effect of nasopharyngeal cancer has improved as a result of continuous improvements in nasopharyngeal cancer diagnosis and treatment methods, the overall 10-year survival is still only approximately $45 \%$, while that of advanced cancer patients is only about $35 \%$ [2]. Nasopharyngeal carcinoma is associated with fast infiltration and growth and high degree of malignancy, and its anatomical location is unique. The early clinical symptoms are not typical, leading to easy misdiagnosis. Studies have found that cervical lymph node metastasis or even distant metastasis may occur early in the onset of nasopharyngeal carcinoma. In addition, local recurrence and distant metastasis after radiotherapy of nasopharyngeal carcinoma are important factors that affect treatment efficacy and prognosis $[3,4]$. Therefore, it is important to study the molecular mechanism involved in metastasis of nasopharyngeal carcinoma so as to identify new molecular markers related to the disease. This will enhance targeted therapy in order to improve the survival of patients and reduce their mortality.

MicroRNA-200c (microrna-200c, miR-200c) is important for epithelial-mesenchymal cell transformation, cell invasion and metastasis in various types of cancer, and in anti-treatment process. However, its role in nasopharyngeal carcinoma, and the mechanism involved are still unclear [5].

This study was carried out to investigate the effect of miR-200c on the biological function of nasopharyngeal carcinoma cells, and the possible molecular regulatory mechanisms involved.

\section{EXPERIMENTAL}

\section{Experimental tissues and cells}

A total of 30 nasopharyngeal carcinoma tissues and para-cancerous normal tissues were taken from patients undergoing surgical treatment in Maternal and Child Health Hospital of Hubei Province, Wuhan from September 2018 to January 2020. Human nasopharyngeal cancer cell line HNE1 was purchased from Shanghai Huiying Biotechnology Co. Ltd.

\section{Main instruments and reagents}

The major instruments and reagents used, and their sources (in brackets) were: real-time fluorescence quantitative PCR instrument (Jinan Guangyao Medical Equipment Co. Ltd., model: CFX384Touch); flow cytometer (Beckman Coulter Co. Ltd, USA: model: CytoFLEX); carbon dioxide incubator (Shanghai Rundu Biotechnology Co. Ltd, model Herocell 180); biological microscope (Beijing Jiayuan Xingye Technology Co. Ltd., model: BS200); constant temperature water bath (Shanghai Chenlian Biotechnology Development Co. Ltd., model: $\mathrm{HH}$ 1); fetal bovine serum (Shenzhen RED Life Science and Technology Co. Ltd.); Transwell Chamber (Beijing Unique Biotech Co. Ltd), and RPMI1640 medium (Shanghai Qiming Biotech Co. Ltd).

\section{Cell culture}

The HNE1 cells were removed from liquid nitrogen, placed in a constant temperature water bath to thaw, centrifuged, and cultured in complete medium in a $5 \% \mathrm{CO}_{2}$ incubator at 37 ${ }^{\circ} \mathrm{C}$. At about $85 \%$ growth, the medium was refreshed, and the cells were subjected to $0.25 \%$ tryptic digestion using $0.25 \%$ trypsin. When the cells become rounded, with clear boundaries, they were sub-cultured.

\section{Cell transfection}

Strains containing empty plasmids and recombinant plasmid PINI were inoculated into $200 \mathrm{~mL}$ of LB medium at a certain ratio, and cultured overnight at $37^{\circ} \mathrm{C}$ in a centrifugal shaker at $200 \mathrm{rpm}$. Thereafter, $200 \mathrm{~mL}$ of bacterial solution was added to the centrifuge tube, and the bacterial cells were recovered via centrifugation at $8000 \mathrm{rpm}$ for $3 \mathrm{~min}$, while the supernatant was discarded. Water droplets were removed using absorbent paper, followed by filtration. Then, isopropanol was added to the filtrate at a volume ratio of $0.3: 1$, mixed and transferred into a CP6 adsorption column, followed by addition of $3 \mathrm{~mL}$ of absolute ethanol and centrifugation at $8000 \mathrm{rpm}$ at room temperature for $3 \mathrm{~min}$. The supernatant was discarded, and the adsorption column CP6 was placed in a clean 50-mL collection tube. Then, 2 $\mathrm{mL}$ of elution buffer was added to the middle part of the adsorption membrane, followed by centrifugation at $8000 \mathrm{rpm}$ for $3 \mathrm{~min}$. The cells were mixed with eluent and kept in a $-20{ }^{\circ} \mathrm{C}$ refrigerator.

Cells with good growth potential were inoculated into a 6-well plate at a density of 100,000 
cells $/ \mathrm{mL}$. When the cells grew to about $70 \%$, they were transfected with either blank plasmid, PINI or miR-200c analogs. After 48-h culture, the control, PINI group, and miR-200c overexpression + PINI groups were obtained, each with 5 replicates.

\section{Real-time fluorescence qPCR}

The miR-200c expressions in nasopharyngeal carcinoma and other tissues were determined with real-time fluorescence quantitative PCR assay. Total RNA was extracted from the nasopharyngeal carcinoma tissues and adjacent normal tissues. The tissues were ground and lysed in lysis buffer, and each supernatant was added to $200 \mu \mathrm{L}$ of chloroform, and mixed well. The mixture was centrifuged, and the white precipitate was added to $1 \mathrm{~mL}$ of $75 \%$ ethanol, followed by thorough mixing, and the absorbance of the solution was read at $270 \mathrm{~nm}$ in an ultraviolet spectrophotometer.

Reverse transcription was performed using a reverse transcription kit. The primer was designed and synthesized, and the samples subjected to real-time fluorescence quantitative PCR in a real-time fluorescence quantitative PCR instrument. The $2^{-} \Delta \Delta^{\mathrm{Ct}}$ method was used to calculate the relative expression level of the target gene.

\section{Western blot assay}

The expression level of PINI in each group of cells was determined with immunoblot assay. Total protein was extracted from the HNE1 cells using TRIzol reagent. Concentration of total protein content of the extract obtained after centrifugation was determined using BCA method. The protein was resolved using SDSPAGE, followed by transfer to PVDF membrane. The membrane was incubated with anti-PINI overnight in a refrigerator at $4{ }^{\circ} \mathrm{C}$, and with HRPlinked $2^{\circ}$ antibody for $60 \mathrm{~min}$ at laboratory temperature. The blots were detected using $\mathrm{ECL}$ method, and gel imaging system was used to determine relative protein expressions. The above assay was conducted multiple times to reduce error.

\section{Transwell migration assay}

This was used to measure changes in cell migration ability in each group of cells. First, 100 $\mu \mathrm{L}$ of double-free medium was used to infiltrate the chamber for $30 \mathrm{~min}$, and absorbent paper was used to dry the medium. Then, $100 \mu \mathrm{L}$ of cell suspension was placed in the upper chamber of the Transwell, while $650 \mu \mathrm{L}$ of complete culture medium was put in the lower chamber. The cells were cultured at $37{ }^{\circ} \mathrm{C}$ for $24 \mathrm{~h}$, after which the chamber was taken out. Then, the cells were stained with hematoxylin-eosin solution, and examined under a light microscope.

\section{Immunofluorescence assays}

Changes in centrosomes in each group of cells were measured using immunofluorescence method. The HNE1 cells were inoculated into a 12-well plate for cell transfection. The cells were fixed with formaldehyde, washed with phosphate buffer, and sealed with BSA blocking solution. After sealing, tubulin monoclonal antibody was dropped on the glass slide and incubated at $4{ }^{\circ} \mathrm{C}$ overnight to avoid the formation of bubbles during the process.

Then, the slide was rinsed with phosphate buffer and incubated in the dark with diluted DyLight488 labeled anti-mouse IgG antibodies. This was followed by DAPI staining and fluorescence microscopic examination. Changes in the centrosomes in each group of cells were recorded.

\section{RESULTS}

\section{MiR-200c expression levels of nasopharyn- geal cancer and para-cancer tissues}

Table 1 shows that miR-200c expression levels in nasopharyngeal carcinoma tissues were significantly increased, when compared with para-cancerous normal tissues $(p<0.01)$.

Table 1: MiR-200c expression levels of nasopharyngeal carcinoma and para-cancerous normal tissues (mean $\pm S D, n=30$ )

\begin{tabular}{ll}
\hline Group & si-stk33 \\
\hline Nasopharyngeal carcinoma tissues & $1.83 \pm 0.35$ \\
Para-cancerous normal tissues & $1.01 \pm 0.21$ \\
$T$ & 11.004 \\
$P$-value & $<0.001$ \\
\hline
\end{tabular}

\section{PINI expression levels of cells}

The PINI expression level in the miR-200c overexpression group was significantly reduced, when compared with the control $(p<0.05)$. However, relative to miR-200c overexpression tissue, PINI expression level in miR-200c overexpression + PINI group was markedly 
elevated $(p<0.05)$. These results are presented in Figure 1 and Table 2.

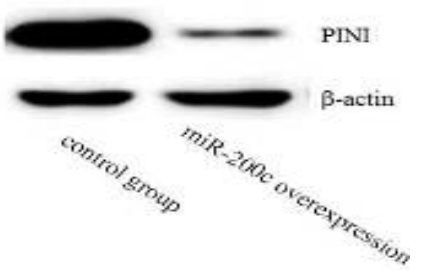

Figure 1: Comparison of PINI expression levels of cells in the two groups

Table 2: PINI expression levels of cells in each group (mean $\pm \mathrm{SD}, \mathrm{n}=30$ )

\begin{tabular}{lc}
\hline Group & PINI \\
\hline Control & $0.41 \pm 0.08$ \\
miR-200c overexpression & $0.10 \pm 0.02$ \\
$F$ & 866.24 \\
$P$-value & $<0.001$ \\
\hline
\end{tabular}

\section{Changes in centrosomes}

The percentage of extra-central somatic cells was markedly increased in the miR-200c overexpression tissue, relative to the control tissue. However, relative to miR-200c overexpression tissue, the percentage of extracentral somatic cells in miR-200c overexpression + PINI tissue was markedly reduced. These results are shown in Table 3.

Table 3: Changes in the centrosome in each group (mean $\pm \mathrm{SD}, \mathrm{n}=30$ )

\begin{tabular}{ll}
\hline Group & $\begin{array}{l}\text { Extra-central } \\
\text { somatic cells (> 2) }\end{array}$ \\
\hline Control & $8.25 \pm 0.24$ \\
MiR-200c & $6.97 \pm 0.17$ \\
overexpression & 550.22 \\
$F$ & $<0.001$ \\
$P$-value & \\
\hline
\end{tabular}

\section{Changes in cell migration capacity}

Relative to the control group, cell migration ability in miR-200c overexpression group was significantly reduced, but cell migration ability was markedly higher in miR-200c overexpression + PINI group than in miR-200c overexpression group $(p<0.05)$. These results are presented in Figure 2 and Table 4.

\section{DISCUSSION}

Nasopharyngeal carcinoma is a malignant tumor which originates from the nasopharyngeal mucosa-covered epithelium. It is a highly lethal tumor and also the most common malignant tumor of the ear, nose, and throat. The pathogenesis of nasopharyngeal carcinoma is relatively complex and not yet clearly understood. It is considered to be a disease caused by a complex interaction of genetic factors, viral infections and environmental factors [6]. Currently, radiotherapy and chemotherapy are the main methods used for the treatment of nasopharyngeal carcinoma. However, most nasopharyngeal carcinoma patients are moderately sensitive to radiation therapy, and their 5-year survival is low, resulting in serious impact on their lives and health [7].

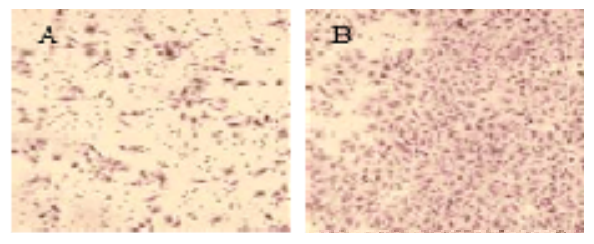

Figure 2: Changes in cell migration ability in each group. A: Control group; B: miR-200c overexpression group

Table 4: Changes in cell migration capacity (mean \pm $\mathrm{SD}, \mathrm{n}=30$ )

\begin{tabular}{lc}
\hline Group & $\begin{array}{c}\text { Cell migration } \\
\text { ability }\end{array}$ \\
\hline Control & $127.36 \pm 14.58$ \\
miR-200c & $72.49 \pm 11.49$ \\
overexpression & 1137.60 \\
$F$ & $<0.001$ \\
$P$-value & $<$ \\
\hline
\end{tabular}

The 5-year survival of patients has not improved significantly, despite new advances in the diagnosis and treatment of nasopharyngeal carcinoma. Therefore, it is highly desirable to identify suitable biomarkers of the disease so as to diagnose early lesions in high-risk groups, and improve the survival of patients.

MicroRNAs (miRNAs) are a new class of endogenous single-stranded non-coding RNA molecules found in eukaryotic organisms. They regulate the expressions of various genes, especially abnormal expression in tumor resistance [8]. Reports have shown that miRNA can be used as an oncogene to down-regulate tumor suppressor genes, and also as a tumor suppressor gene to down-regulate oncogenes, with diverse miRNAs regulating different types of tumors [9]. In addition, miRNAs affect the posttranscriptional regulation of target genes, thereby changing the target protein mRNA, which in turn affects the sensitivity of tumor cells to drugs [10].

The miR-200 group is a vital part of miRNAs. Their expressions not only regulate cell 
proliferation, but also reduce cell migration and invasion by targeting ZEB1 and ZEB2 [11]. In particular, it has been discovered that dysregulated expression of miR-200c in a variety of cancer cell lines affects a large variety of different biological processes. According to reports, miR-200c plays an important role in epithelial-mesenchymal cell transformation, cell invasion, and metastasis [12]. The results of this study indicate that miR-200c may be involved in the pathogenesis of nasopharyngeal carcinoma.

It is known that PINI is a highly conserved peptidyl-prolyl cis-trans isomerase that specifically recognizes phosphorylated serine/threonine-proline motifs and causes cistrans isomerization. It has been reported that $\mathrm{PINI}$ is highly expressed in most tumors [13]. Some scholars have found in the study of breast cancer that PINI enhances the transcriptional effect of c-Jun through the Ras signaling pathway, thereby enhancing cell migration [14]. Migratory and invasive potential are vital attributes of cancer cells, and they are complex, multi-step cascade processes linked to the prognosis of patients.

The centrosome is an important indicator of cancer, and it plays a vital role in microtubule organization, signal transduction and cell division. Studies have found abnormal centrosome amplification in tumor cells: cancer cells with centrosome amplification usually survive in cell division and cause genomic instability [15].

\section{CONCLUSION}

The findings of this study demonstrate that miR200c may inhibit the migration ability of nasopharyngeal carcinoma cells and also inhibit abnormal expansion of centrosomes by suppressing the expression of PINI. Thus, PINI may be a target gene of miR-200c.

\section{DECLARATIONS}

\section{Conflict of interest}

No conflict of interest is associated with this work.

\section{Contribution of authors}

We declare that this work was done by the author(s) named in this article and all liabilities pertaining to claims relating to the content of this article will be borne by the authors. All authors read and approved the manuscript for publication. Wenxia He conceived and designed the study, Sheng $\mathrm{Xu}$, Wenxia He collected and analyzed the data, while Sheng $\mathrm{Xu}$ wrote the manuscript.

\section{Open Access}

This is an Open Access article that uses a funding model which does not charge readers or their institutions for access and distributed under the terms of the Creative Commons Attribution License (http://creativecommons.org/licenses/by/ 4.0) and the Budapest Open Access Initiative (http://www.budapestopenaccessinitiative.org/rea d), which permit unrestricted use, distribution, and reproduction in any medium, provided the original work is properly credited.

\section{REFERENCES}

1. Cao Y, Chan KI, Xiao G, Chen Y, Qiu X, Hao H, Mak SC, $L$ in TY. Expression and clinical significance of $P D-L 1$ and BRAF expression in nasopharyngeal carcinoma. BMC Cancer 2019; 19(1): 1022.

2. Wang BC, Xiao BY, Lin GH, Wang C, Liu Q. The efficacy and safety of induction chemotherapy combined with concurrent chemoradiotherapy versus concurrent chemoradiotherapy alone in nasopharyngeal carcinoma patients: a systematic review and meta-analysis. BMC Cancer 2020; 20(1): 393.

3. Hong RL, Hsiao CF, Ting LL, Ko JY, Wang CW, Chang JTC, Lou PJ, Wang HM, Tsai MH, Lai SC, et al. Final results of a randomized phase III trial of induction chemotherapy followed by concurrent chemoradiotherapy versus concurrent chemoradiotherapy alone in patients with stage IVA and IVB nasopharyngeal carcinoma-Taiwan Cooperative Oncology Group (TCOG) 1303 Study. Ann Oncol 2018; 29(9): 19721979.

4. Li YF, Ding JW, Liao LM, Zhang ZL, Liao SS, Wu Y, Zhou $D Y$, Liu AW, Huang L. Expression of programmed death ligand-1 predicts poor outcome in nasopharyngeal carcinoma. Mol Clin Oncol 2017; 7(3): 378-382.

5. Ali Syeda Z, Langden SSS, Munkhzul C, Lee M, Song SJ. Regulatory Mechanism of MicroRNA Expression in Cancer. Int J Mol Sci 2020; 21(1): 1723.

6. Zhuo $X$, Zhou $W$, Ye $H$, Li D, Chang A, Wu Y, Zhou Q. Screening of key miRNAs and evaluation of their diagnostic and prognostic values in nasopharyngeal carcinoma. Oncol Lett 2019; 17(6): 5803-5810.

7. Zhang Y, Fan J, Fan Y, Li L, He X, Xiang Q, Mu JH, Zhou $D F$, Sun $X J$, Yang $Y C$, et al. The new 6q27 tumor suppressor DACT2, frequently silenced by $\mathrm{CpG}$ methylation, sensitizes nasopharyngeal cancer cells to paclitaxel and 5-FU toxicity via $\beta$-catenin/Cdc25c signaling and G2/M arrest. Clin Epigenetics 2018; 10(1): 26. 
8. Zeng $Z$, Huang $H$, Huang $L$, Sun $M$, Yan $Q$, Song $Y$, Wei $F$, Bo $H$, Gong Z, Zeng $Y$, et al. Regulation network and expression profiles of Epstein-Barr virus-encoded microRNAs and their potential target host genes in nasopharyngeal carcinomas. Sci China Life Sci 2014; 57(3): 315-326.

9. Zhuo X, Zhou W, Ye H, Li D, Chang A, Wu Y, Zhou Q. Screening of key miRNAs and evaluation of their diagnostic and prognostic values in nasopharyngeal carcinoma. Oncol Lett 2019; 17(6): 5803-5810.

10. Fan $C$, Tang $Y$, Wang J, Xiong $F$, Guo $C$, Wang $Y$, Xiang $B$, Zhou M, Li X, Wu X, et al. The emerging role of Epstein-Barr virus encoded microRNAs in nasopharyngeal carcinoma. J Cancer 2018; 9(16): 2852-2864.

11. Cao W, Sun JW. MicroRNA-200c promotes tumor cell proliferation and migration by directly targeting dachshund family transcription factor 1 by the Wnt/ $\beta$ - catenin signaling pathway in nasopharyngeal carcinoma. Anti Cancer Drugs 2019; 30(1): 218-224.

12. Yang B, Liu Y, Li L, Deng H, Xian L. MicroRNA-200a promotes esophageal squamous cell carcinoma cell proliferation, migration and invasion through extensive target genes. Mol Med Rep 2020; 21(1): 2073-2084.

13. Zhang J, Jia L, Tsang CM, Tsao SW. EBV Infection and Glucose Metabolism in Nasopharyngeal Carcinoma. Adv Exp Med Biol 2017; 1018(2): 75-90.

14. Kim G, Bhattarai PY, Choi HS. Peptidyl-prolyl cis/trans isomerase NIMA-interacting 1 as a molecular target in breast cancer: a therapeutic perspective of gynecological cancer. Arch Pharm Res 2019; 42(9): 128-139.

15. Liu J, Li M, Liu X, Liu F, Zhu J. miR-27a-3p promotes the malignant phenotypes of osteosarcoma by targeting teneleven translocation 1. Int J Oncol 2018; 52(2): 12951304. 